\title{
Allergens and endotoxin on mothers' mattresses and total immunoglobulin $E$ in cord blood of neonates
}

\author{
J. Heinrich*, G. Bolte*, B. Hölscher*, J. Douwes", I. Lehmann", B. Fahlbusch', W. Bischof ${ }^{\S}$, \\ M. Weiss ${ }^{f}$, M. Borte**, H-E. Wichmann*, on behalf of the LISA study group
}

Allergens and endotoxin on mothers' mattresses and total immunoglobulin $E$ in cord blood of neonates. J. Heinrich, G. Bolte, B.Hölscher, J. Douwes, I. Lehmann, B. Fahlbusch, W. Bischof, M. Weiss, M. Borte, H-E. Wichmann, on behalf of the LISA study group. (C) ERS Journals Ltd 2002.

ABSTRACT: The current authors examined whether mite and cat allergen and bacterial endotoxin levels in dust of the mothers' mattresses were associated with cord blood immunoglobulin (Ig)E (CB-IgE) levels in newborns.

Data from 1,332 term and normal weight neonates, from an ongoing birth cohort study, Influences of life-style related factors on the immune system and the development of allergies in childhood (LISA), with complete information on exposure to biocontaminants in mattress dust and CB-IgE were analysed.

Two thirds of CB-IgE were undetectable $\left(<0.35 \mathrm{kU} \cdot \mathrm{L}^{-1}\right)$. Thus, 0.35 and $0.45 \mathrm{kU} \cdot \mathrm{L}^{-1}$ (4th quartile) were chosen as cut-offs. Nonparametric smoothing (generalised additive models) showed statistically significant confounder-adjusted associations between elevated CB-IgE levels $\left(\geqslant 0.45 \mathrm{kU} \cdot \mathrm{L}^{-1}\right)$ and $\log$-transformed exposures to cat (linear), mite (inverse u-shaped), and endotoxin (u-shaped).

After adjustment for covariables, elevated CB-IgE levels (logistic regression using the 1st-4th quartiles of exposure) were positively associated with high cat-allergen exposure and medium exposure to mite allergen, but were inversely associated with exposure to endotoxin. The associations were similar, but somewhat weaker, when $0.35 \mathrm{kU} \cdot \mathbf{L}^{-1}$ was used as cut-off.

These results, showing an association between prenatal allergen and endotoxin exposures and immunoglobulin $E$ production, suggest that the development of foetal immune responses may be affected.

Eur Respir J 2002; 20: 617-623.

\begin{abstract}
*GSF-Institute of Epidemiology, National Research Centre for Environment and Health, Neuherberg, Germany. ${ }^{\#}$ Institute for Risk Assessment Sciences (IRAS), Division of Environmental and Occupational Health, Utrecht University, Utrecht, the Netherlands. "Dept of Human Exposure Research and Epidemiology, UFZ-Centre for Environmental Research Leipzig-Halle Ltd, Leipzig, ${ }^{+}$Institute of Clinical Immunology, University of Jena, Jena and ${ }^{\S}$ Dept of Indoor Climatology (ark), University of Jena, Erfurt, ${ }^{\mathrm{D}} \mathrm{Dr}$ von Haunersches Kinderspital, University of Munich, Munich, and **Dept of Paediatrics, University of Leipzig, Leipzig, Germany.
\end{abstract}

Correspondence: J. Heinrich, GSFInstitute of Epidemiology, Ingolstaedter Landstr. 1, D-85764 Neuherberg, Germany.

Fax: 498931873380

E-mail: Joachim.Heinrich@gsf.de

Keywords: Cat allergen, cord blood immunoglobulin E, endotoxin, house dust, mite allergen, prenatal exposures

Received: November 262001

Accepted after revision: April 152002
Atopy is believed to be an important determinant in the development of asthma. Therefore, environmental factors that drive the immune response into an atopic direction need further investigation. There is an increasing body of evidence that suggests that the development of an atopic immune response may begin during foetal life [1]. A complex interplay between a genetically-defined susceptibility and environmental exposure is assumed to determine the occurrence and further progression of disease [1]. Allergen-specific T-cells, i.e. specific for cows' milk, hen's eggs and, more surprisingly, house-dust mites, have been detected at birth, thus suggesting that prenatal allergen exposure may affect the development of the immune system [2-6]. Allergen contact in utero may prime the foetal immune system, resulting in a decreased capacity of T-helper (Th) 1 cytokine interferon (IFN) $-\gamma$ production, which may cause atopic Th2 immune responses in neonates [7]. Moreover, it has been postulated that maternal cytokines may be able to influence the development of foetal immune responses $[8,9]$.

Since the foetus is not directly exposed to environmental allergens, it has been suggested that interaction between mother and foetus occurs and that small amounts of antigens or antigen-derived peptides may cross the placenta [10]. JONES et al. [1] and WARNER et al. [2] have proposed the presence of allergens in amniotic fluid as a possible mechanism of this maternal/foetal interaction. Recently published results have provided further support for the hypothesis that transamniotic and transplacental allergen exposures have an effect on foetal antigen-specific T-cell activity [4-6].

In addition to allergens, bacterial endotoxin in house dust may play a role in the development of the atopic immune response. It has recently been suggested that endotoxin exposure early in life may have 
a protective effect on the development of atopy by enhancing Th1 immunity $[10,11]$. Some evidence has been presented recently by GEREDA et al. [12], in a small study among 61 infants with a high risk for developing asthma, which showed that allergen-sensitised infants had significantly lower house-dust endotoxin levels than nonsensitised infants,. The authors further demonstrated that endotoxin levels correlated with IFN- $\gamma$-producing T-cells (Th1), but not with interleukin (IL)-4, IL-5 or IL-13 producing cell proportions (Th2) in a subset of these infants. However, no other direct evidence for this hypothesis is currently available and no studies focusing on prenatal endotoxin exposure in relation to atopy have been published.

A number of studies have shown an association between prenatal allergen exposure and allergenspecific reactivity in cord blood [4-6], but none of the studies have provided evidence of the effects of total cord blood immunoglobulin (Ig)E (CB-IgE) exposure to biocontaminants. Although CB-IgE may not predict atopic diseases in later life [13], elevated CB-IgE levels might indicate stimulation of T-cell responses in utero. Therefore, the present authors analysed the relationship between perinatal exposure to cat and mite allergens and endotoxin, assessed as dust concentrations of the mothers' mattresses, and total CB-IgE, a reflection of the general Th2 activation in the neonatal immune system. For this purpose, data from an ongoing birth cohort study, originally designed to assess "Influences of life-style related factors on the immune system and the development of allergies in childhood" (LISA), were used.

\section{Methods}

Newborns from six obstetrical clinics in Munich (western Germany) and all four obstetrical clinics in Leipzig (eastern Germany) were defined as the target population for the study. In total, 2,443 neonates were recruited between December 1997 and January 1999. Neonates displaying at least one of the following criteria were excluded from the study: preterm birth (maturity $<37$ gestational weeks), low birth weight $(<2,500 \mathrm{~g})$, congenital malformation, symptomatic neonatal infection, antibiotic medication, hospitalisation or intensive medical care during neonatal period. In addition, newborns from mothers with immunerelated diseases (autoimmune disorders, diabetes, hepatitis B), on long-term medication or who abuse drugs and/or alcohol, and newborns from parents with a nationality other than German or who were not born in Germany, were excluded. The overall response rate was $55 \%$.

Questionnaire data on family history of atopy, parental education, health problems during pregnancy, smoking during pregnancy and exposure to environmental tobacco smoke during pregnancy at home were collected. After birth, $4 \mathrm{~mL}$ of venous cord blood was collected and centrifuged at $1,400 \times g$ for $10 \mathrm{~min}$. The serum was stored at $-20^{\circ} \mathrm{C}$ until analysis. House dust on the mothers' mattresses was sampled within 3 months of the birth. Dust samples were taken by vacuuming $1 \mathrm{~m}^{2}$ of the mothers' mattresses for
2 min. Dust was collected on cellulose filters using ALK sampling devices (ALK allergen mouthpiece; ALK, Hørsholm, Denmark) and was stored at $-20^{\circ} \mathrm{C}$ until extraction. The methods of dust collection and extraction have been described previously [14]. The concentrations of cat and mite allergens (expressed per $g$ of mattress dust) and endotoxin (expressed in endotoxin units (EU) per g of mattress dust) were used as a proxy for perinatal exposure. A complete set of data on allergens and endotoxin levels, serum CB-IgE and questionnaires was available for 1,332 children. The study was approved by the ethics committees of the Landesaerztekammer Bavaria (Bavaria, Germany) and of the University of Leipzig (Leipzig, Germany).

\section{Laboratory analyses}

Total-serum IgE was determined with the Pharmacia system (neonate IgE kit; Pharmacia, Freiburg, Germany). The limit of detection was $0.35 \mathrm{kU} \cdot \mathrm{L}^{-1}$. $\mathrm{IgA}$ was also determined in order to exclude cord blood contaminated by the mothers' blood [15]. No single IgA level exceeded the cut-off point of $32 \mu \mathrm{g} \cdot \mathrm{L}^{-1}$. Three arbitrary categories were set for elevated CB-IgE: $\geqslant 0.35 \mathrm{kU} \cdot \mathrm{L}^{-1}$ (above the detection limit), $\geqslant 0.45 \mathrm{kU} \cdot \mathrm{L}^{-1}(>75 \mathrm{th}$ percentile $)$, and $\geqslant 0.90 \mathrm{kU} \cdot \mathrm{L}^{-1}$.

The levels of mite allergens Der p 1 (Dermatophagoides pteronyssinus) and Der f 1 (Dermatophagoides farinae) and of cat allergen Fel d 1 were measured with a two-site monoclonal antibody enzyme-linked immunosorbent assay, according to the instructions of the manufacturer (Indoor Biotechnologies, Clwyd, UK) [16].

Sterile and pyrogen-free glassware, pipette tips and microtitre plates were used. Endotoxin was assayed with a quantitative kinetic chromogenic Limulus Amebocyte Lysate (LAL) method (Kinetic-QCL no. 50-650U, LAL lot no. 5L3480; Bio Whittaker, Walkersville, MD, USA) at $37^{\circ} \mathrm{C}$ [16]. Analyses were performed with an automated microtitre plate reader (anthos ht III; Anthos Labtec Instruments, Salzburg, Austria) and WinKQCL 1.1 software (Bio Whittaker). Escherichia coli endotoxin (lot no. 5L1570; Bio Whittaker) was used as standard endotoxin. The endotoxin potency of this standard was $14.5 \mathrm{EU} \cdot \mathrm{ng}^{-1}$. Diluted samples were initially analysed in inhibition or enhancement mode and a dilution rate of 1:1,000 was found to be appropriate for further analysis in routine mode. All measurements were performed in duplicate. Analyses were repeated if the difference between sample duplicates exceeded $10 \%$. No single measured endotoxin level was below the limit of detection of $3.5 \mathrm{ng} \cdot \mathrm{g}^{-1}$.

\section{Statistical methods}

In the descriptive part of the analysis, the Chisquared test was employed to compare crude prevalence rates, and $\mathrm{F}$ tests were used to compare log-transformed concentrations of biocontaminants. Rank correlations were calculated to quantify the associations between allergen and endotoxin concentrations. 
Allergen concentrations less than the detection limit $\left(10 \mathrm{ng} \cdot \mathrm{g}^{-1}\right.$ for Der $\mathrm{p} 1$ and Der $\mathrm{f} 1$, and $15 \mathrm{ng} \cdot \mathrm{g}^{-1}$ for Fel d 1) were assigned a value of one-half of the detection limit. This occurred in $11 \%$ of the dust samples for the cat allergen, while in $15 \%$ of the samples, the allergen concentrations of both mites were below the limit of detection.

For an initial examination of the relationship between elevated CB-IgE and biocontaminants, logistic regression models with dummy variables for four quartiles of each exposure variable were applied. The following potential confounders were controlled for: area (Leipzig, Munich), sex, smoking during pregnancy in the second or third trimester, environmental tobacco smoke (ETS) during the second or third trimester at home, socio-economic status (SES, defined by parental education), family history of atopy and mutual exposure to biocontaminants.

A nonparametric logistic regression approach [17] was used to further investigate the association between elevated CB-IgE and biocontaminants. In this approach, the pattern of the relationship between the prevalence of elevated CB-IgE and, for example, the endotoxin concentration is not given in advance but is estimated from the data with smooth functions. Therefore, it is possible to capture both linear and nonlinear associations. Adjustments for potential confounders can be incorporated as in logistic analyses.

S-Plus was used to estimate smooth functions of the log-concentrations of the biocontaminants with loess smoothers $(\operatorname{span}=0.8)$ within a generalised additive model. The curves and point-wise standard error bands were first computed on the logit scale and then transformed to prevalences by adding the intercept (the mean of the logits in the coding of S-Plus) and applying the inverse logit function.

The results are presented as figures showing estimated prevalences of elevated CB-IgE for various concentrations of the biocontaminants (fig. 1). Corresponding standard error bands are also provided. The prevalences in each of the diagrams were computed for an average concentration of the other biocontaminants. For example, in the third plot, the estimated prevalence of $30 \%$ for elevated CB-IgE at the minimum endotoxin concentration corresponds to average concentrations of the mite and cat allergens. The estimated prevalence at a given biocontaminant concentration is based on the proportion of elevated CB-IgE levels in a group of children with "similar" concentration values. For very high concentrations, only a few children with similar values were available. As a consequence, there are wider standard error bands in the far right of the plots.

\section{Results}

Among the 1,332 neonates included in the analyses, $32.1 \%$ had CB-IgE levels $>0.35 \mathrm{kU} \cdot \mathrm{L}^{-1}$ and $13.9 \%$ had CB-IgE levels $>0.90 \mathrm{kU} \cdot \mathrm{L}^{-1}$ (table 1). There was a wide range in the concentrations of dust-mite allergen, cat allergen and endotoxin in mattress dust (fig. 1). Biocontaminant levels were moderately correlated with the following correlation coefficients: $r=0.34$
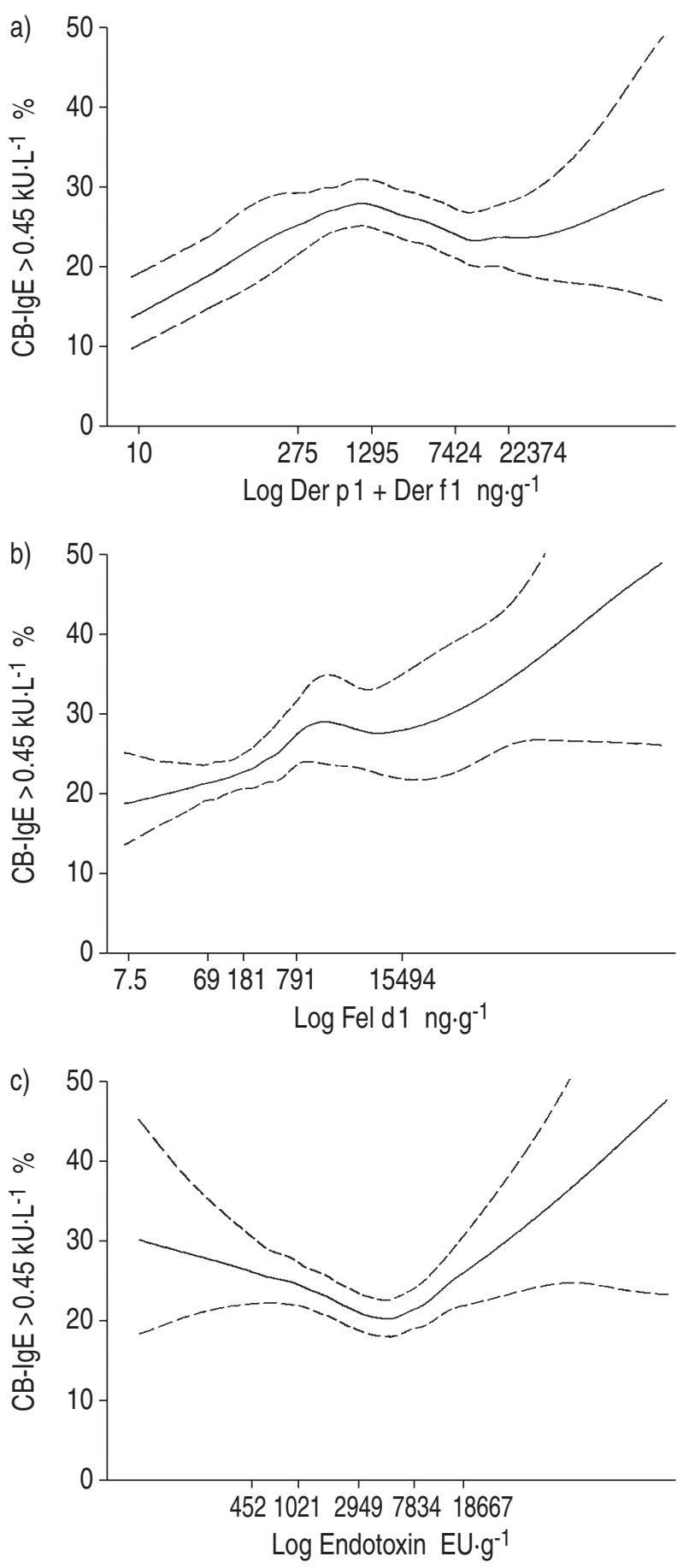

Fig. 1.-Adjusted smoothed associations between prevalence of elevated cord blood immunoglobulin E (CB-IgE; $\left.\geqslant 0.45 \mathrm{kU} \cdot \mathrm{L}^{-1}\right)$ and concentrations of a) mite allergens (Der $\mathrm{p} 1$ and Der $\mathrm{f} 1$ ), b) cat allergen (Fel d 1) and c) endotoxin. Solid curves show prevalences, dashed curves represent point-wise \pm 2 SE bands. Tick marks on the horizontal axis are shown at 10th, 25th, 50th, 75th and 90th percentiles. Prevalences are adjusted for area, sex, smoking during pregnancy, environmental tobacco smoke at home, parental education, family history of atopy and mutually for exposure to biocontaminants $(n=1241)$. EU: endotoxin units.

$(\mathrm{p}<0.001)$ for Der $\mathrm{p} 1$ and Der $\mathrm{f} 1 ; \mathrm{r}=0.10(\mathrm{p}<0.001)$ for Der $\mathrm{p} 1$ and Fel d 1; $\mathrm{r}=0.18(\mathrm{p}<0.001)$ for Der $\mathrm{p} 1$ and endotoxin; $r=0.11(p<0.001)$ for Der $\mathrm{f} 1$ and Fel d $1 ; \mathrm{r}=0.17$ 
Table 1.-Characteristics of the study population: newborns from the cities of Munich (Germany) and Leipzig (Germany) with complete information on cord blood immunoglobulin (Ig) $\mathrm{E}$ and biocontaminants in mattress dust in 1998-1999

\begin{tabular}{lcc}
\hline & $\begin{array}{c}\text { Prevalence } \\
\%\end{array}$ & $\begin{array}{c}\text { Frequency } \\
\mathrm{n} / \mathrm{N}\end{array}$ \\
\hline Munich & 56.1 & $747 / 1332$ \\
Leipzig & 43.9 & $585 / 1332$ \\
Males & 51.9 & $691 / 1332$ \\
Parental education ${ }^{\#}$ & 23.4 & $308 / 1316$ \\
$\quad$ Low & 18.5 & $244 / 1316$ \\
Medium & 58.1 & $764 / 1316$ \\
High & & \\
Parental atopy & 47.7 & $633 / 1328$ \\
$\quad$ None & 35.7 & $474 / 1328$ \\
Mother & 32.6 & $409 / 1256$ \\
Father & 38.2 & $507 / 1328$ \\
Mother or father & 14.2 & $188 / 1328$ \\
$\quad$ Both & 10.4 & $131 / 1263$ \\
Smoking & 17.7 & $224 / 1267$ \\
$\quad$ During pregnancy & \\
ETS at home & & \\
Cord blood & 32.1 & $427 / 1332$ \\
$\quad \geqslant 0.35 \mathrm{kU} \cdot \mathrm{L}^{-1}$ & 24.8 & $330 / 1332$ \\
$\quad \geqslant 0.45 \mathrm{kU} \cdot \mathrm{L}^{-1}(4$ th quartile) & 13.9 & $185 / 1332$ \\
$\quad \geqslant 0.90 \mathrm{kU} \cdot \mathrm{L}^{-1}$ &
\end{tabular}

$\mathrm{n}$ : available data; $\mathrm{N}$ : total sample size; ETS: environmental tobacco smoke. ${ }^{\#}$ : low $<10$ grades, medium 10 grades, high $>10$ grades; ": life-time prevalence of asthma, hay fever or atopic eczema; ${ }^{+}$: during second or third trimester; ${ }^{f}$ : limit of detection.

$(\mathrm{p}<0.001)$ for Der $\mathrm{f} 1$ and endotoxin; and $\mathrm{r}=0.16(\mathrm{p}<$ 0.001 ) for Fel d 1 and endotoxin. Biocontaminant levels were associated with several potential confounding factors, such as area (mite and cat allergen), parental education (cat allergen only), family history of atopy (cat allergen only), and exposure to tobacco smoke (mite and cat allergen) (table 2).

Figure 1 shows the confounder-adjusted smoothed associations between prevalence of elevated CB-IgE $\left(\geqslant 0.45 \mathrm{kU} \cdot \mathrm{L}^{-1}\right)$ and exposure to biocontaminants. The adjusted prevalence of elevated CB-IgE showed an almost continuous increase with increasing catallergen exposure, whereas in the case of endotoxin exposure, the curve looked u-shaped. For exposure to mites, an inverse u-shaped association was observed. However, for very high concentrations of mite allergens, the association showed wide standard error bands. Using approximate tests based on the deviance [17], it was found that all three associations were significant at the 5\% level. Furthermore, the relationship between logits and log-exposure differed significantly from linearity for mites and endotoxin.

Similar plots were fitted for CB-IgE $\geqslant 0.35 \mathrm{kU} \cdot \mathrm{L}^{-1}$. They showed similar, but slightly weaker associations (data not shown).

In addition, tables 3 and 4 present crude prevalences and mutually-adjusted odds ratios (OR) for the four quartiles of each exposure variable. The findings of the parametric logistic regression model for detectable $\left(\geqslant 0.35 \mathrm{kU} \cdot \mathrm{L}^{-\mathrm{I}}\right)$ and elevated $\mathrm{CB}-\mathrm{IgE}$ $\left(\geqslant 0.45 \mathrm{kU} \cdot \mathrm{L}^{-1}\right)$ are consistent with figure 1 .

After adjustment for covariables, elevated CB-IgE values ( $\geqslant 4$ th quartile: $0.45 \mathrm{kU} \cdot \mathrm{L}^{-1}$ ) were positively associated with high exposure to cat allergen (4th versus 1 st quartile: $\mathrm{OR}=1.76,95 \%$ confidence interval (CI) 1.20-2.60) and medium exposure to mite allergen (2nd versus 1st quartile: $\mathrm{OR}=1.96,95 \%$ CI $1.32-2.90$; 3rd versus 1st quartile: $\mathrm{OR}=1.79,95 \%$ CI 1.19-2.67),

Table 2. - Geometric means (GM) of biocontaminants in mothers' mattress dust samples related to potential confounders

\begin{tabular}{|c|c|c|c|c|}
\hline & $\mathrm{N}$ & $\begin{array}{c}\text { Der p } 1+\text { Der f } 1 \\
{\mathrm{ng} \cdot \mathrm{g}^{-1}}_{\mathrm{GM}}\end{array}$ & $\begin{array}{l}\text { Fel d } 1 \\
\text { ng.g } \\
\text { GM }\end{array}$ & $\begin{array}{c}\text { Endotoxin } \\
\text { EU.g-1 } \\
\text { GM }\end{array}$ \\
\hline \multicolumn{5}{|l|}{ Study area } \\
\hline Munich & 747 & $827 * * *$ & $248 * * *$ & 2831 \\
\hline Leipzig & 585 & $1487 * * *$ & $417 * * *$ & 2960 \\
\hline \multicolumn{5}{|l|}{ Sex } \\
\hline Males & 691 & 978 & 339 & 2978 \\
\hline Females & 641 & 1179 & 285 & 2793 \\
\hline \multicolumn{5}{|l|}{ Parental education ${ }^{\#}$} \\
\hline Low & 308 & 1014 & $610 * * *$ & 2690 \\
\hline High & 244 & 810 & $466^{* * * *}$ & 2734 \\
\hline Very high & 764 & 1210 & $207 * * *$ & 3003 \\
\hline \multicolumn{5}{|l|}{ Family atopy } \\
\hline None & 633 & 1173 & $398 * *$ & 3136 \\
\hline Mother or father & 507 & 998 & $265^{* *}$ & 2672 \\
\hline Both & 188 & 984 & $217 * *$ & 2688 \\
\hline \multicolumn{5}{|c|}{ Smoking during pregnancy $^{+}$} \\
\hline No & 1132 & 1142 & $285^{* * *} *$ & 2862 \\
\hline Yes & 131 & 720 & $710^{* * *}$ & 3129 \\
\hline \multicolumn{5}{|c|}{ ETS at home during pregnancy ${ }^{+}$} \\
\hline No & 1043 & $1165^{*}$ & $267 * * *$ & 2833 \\
\hline Yes & 224 & $787^{*}$ & $694 * * *$ & 2978 \\
\hline
\end{tabular}

ETS: environmental tobacco smoke; EU: endotoxin units. ${ }^{\#}$ : low $<10$ grades, high 10 grades, very high $>10$ grades; ${ }^{\circ}$ : life-time prevalence of asthma, hay fever, or atopic eczema; ${ }^{+}$: during second or third trimester. ${ }^{*}: \mathrm{p}<0.05 ; * *: \mathrm{p}<0.01 ; *^{* *}: \mathrm{p}<0.001$, $\mathrm{F}$ tests for log-transformed concentrations. 
Table 3.-Crude prevalence of elevated cord blood immunoglobulin $\mathrm{E}$ (CB-lgE) by biocontaminants in mothers' mattress dust samples

\begin{tabular}{|c|c|c|}
\hline & $\begin{array}{c}\text { CB-IgE } \\
\geqslant 0.35 \mathrm{kU} \cdot \mathrm{L}^{-1}\end{array}$ & $\begin{array}{c}\text { CB-IgE } \\
\geqslant 0.45 \mathrm{kU} \cdot \mathrm{L}^{-1}\end{array}$ \\
\hline \multicolumn{3}{|l|}{ Der $\mathrm{p} 1+\operatorname{Der} \mathrm{f} 1$} \\
\hline$<25$ th perc. & 27.0 & 18.9 \\
\hline 25 th -50 th perc. & 37.2 & 30.0 \\
\hline 50th -75 th perc. & 33.3 & 25.2 \\
\hline$\geqslant 75$ th perc. & 30.6 & 24.9 \\
\hline p-value & 0.036 & 0.011 \\
\hline \multicolumn{3}{|l|}{ Fel d 1} \\
\hline$<25$ th perc. & 27.6 & 20.1 \\
\hline 25 th -50 th perc. & 32.1 & 23.7 \\
\hline 50th-75th perc. & 30.9 & 24.0 \\
\hline$\geqslant 75$ th perc. & 37.5 & 31.2 \\
\hline p-value & 0.051 & 0.009 \\
\hline \multicolumn{3}{|l|}{ Endotoxin } \\
\hline$<25$ th perc & 33.1 & 25.6 \\
\hline 25 th -50 th perc. & 30.3 & 23.7 \\
\hline 50th-75th perc. & 28.5 & 20.4 \\
\hline$\geqslant 75$ th perc. & 36.1 & 29.5 \\
\hline p-value & 0.166 & 0.053 \\
\hline
\end{tabular}

perc.: percentile. ${ }^{\#}$ : Chi-squared test for homogeneity of proportions.

but were inversely related to medium exposure to endotoxin (3rd versus 1st quartile: $\mathrm{OR}=0.66$, 95\% CI 0.44-0.97).

No significant associations with exposure were found when a cut-off of $\geqslant 0.90 \mathrm{kU} \cdot \mathrm{L}^{-1}$ was used to define elevated CB-IgE (data not shown).

The effect estimates for each single biocontaminant were not confounded by any of the other biocontaminants, because mutual adjustment for the other biocontaminants only marginally changed the OR. Exposure to biocontaminants, expressed per square $\mathrm{m}$, instead of per $\mathrm{g}$ dust, did not significantly alter the associations found with CB-IgE (data not shown).

Sensitivity analyses stratified for children with and without a family history of asthma, hay fever or atopic eczema, showed similar effect estimates for the association between CB-IgE and exposure to biocontaminants (data not shown). Furthermore, stratified analyses for children with maternal atopy history versus paternal atopy history did not indicate effect modification.

\section{Discussion}

To the current authors' knowledge, this study reports, for the first time, an association between CB-IgE levels and log-transformed mothers' exposure to biocontaminants. Nonparametric smoothing showed a statistically significant quadratic term, which indicates an inverse $u$-shaped association between mite exposure and elevated CB-IgE (fig. 1). Analogously, the association between exposure to endotoxin and elevated CB-IgE was better analysed by a nonparametric approach. However, the association between exposure to cat allergen and CB-IgE was best described by a monotonic linear equation even when nonparametric models were applied.

Logistic regression analyses resulted in similar findings: a positive linear association with high exposure to cat allergen, an inverse u-shaped association with mite exposure, and a u-shaped association with endotoxin concentration on the mothers' mattress dust.

Measurable CB-IgE levels indicate that the foetus is able to produce $\operatorname{IgE}$, since $\operatorname{IgE}$ does not cross the placenta [1], and thus, elevated CB-IgE levels indicate stimulation of T-cell responses in utero. Foetal production of IgE might occur as early as 11 weeks of gestation [1]. Recent research showed that the foetus can already produce IgE antibodies against cows' milk, hen's eggs and also dust mites at 22 weeks of gestation [2, 18]. In vitro studies with cord blood lymphocytes from neonates delivered to helmintheinfected mothers in Kenya, showed production of total IgE and parasite antigen-specific IgE [19]. These

Table 4. - The association of elevated cord blood immunoglobulin $\mathrm{E}$ (CB-lgE) with concentrations of biocontaminants in mothers' mattress dust samples: 1241 newborns from Munich and Leipzig, Germany, 1998-1999

\begin{tabular}{|c|c|c|}
\hline & $\mathrm{CB}-\mathrm{IgE} \geqslant 0.35 \mathrm{kU} \cdot \mathrm{L}^{-1}$ & $\mathrm{CB}-\operatorname{IgE} \geqslant 0.45 \mathrm{kU} \cdot \mathrm{L}^{-1}$ \\
\hline \multicolumn{3}{|l|}{ Der p $1+\operatorname{Der} f 1$} \\
\hline$<25$ th perc. & 1 & 1 \\
\hline 25 th-50th perc. & $1.67(1.17-2.38)$ & $1.96(1.32-2.90)$ \\
\hline 50 th -75 th perc. & $1.62(1.12-2.33)$ & $1.79(1.19-2.67)$ \\
\hline$\geqslant 75$ th perc. & $1.23(0.85-1.79)$ & $1.50(0.99-2.25)$ \\
\hline \multicolumn{3}{|l|}{ Fel d 1} \\
\hline$<25$ th perc. & 1 & 1 \\
\hline 25 th-50th perc. & $1.05(0.73-1.50)$ & $1.09(0.74-1.61)$ \\
\hline 50 th -75 th perc. & $1.10(0.76-1.57)$ & $1.19(0.80-1.77)$ \\
\hline$\geqslant 75$ th perc. & $1.43(1.00-2.04)$ & $1.76(1.20-2.60)$ \\
\hline \multicolumn{3}{|l|}{ Endotoxin } \\
\hline$<25$ th perc. & 1 & 1 \\
\hline 25 th-50th perc. & $0.89(0.63-1.26)$ & $0.86(0.59-1.26)$ \\
\hline 50 th-75th perc. & $0.81(0.56-1.15)$ & $0.66(0.44-0.97)$ \\
\hline$\geqslant 75$ th perc. & $1.08(0.76-1.53)$ & $1.02(0.71-1.48)$ \\
\hline
\end{tabular}

Data are presented as adjusted odds ratios ${ }^{\#}\left(95 \%\right.$ confidence intervals). perc.: percentile. ${ }^{\#}$ : adjusted for area, sex, smoking during pregnancy, environmental tobacco smoke at home, parental education, family history of atopy (mother's or father's life-time prevalence of asthma, hay fever or atopic eczema), and mutually adjusted for exposure to biocontaminants. 
findings indicate that antigen-specific immunity starts to develop in utero.

Although no single IgA level in cord blood exceeded the cut-off point of $32 \mu \mathrm{g} \cdot \mathrm{L}^{-1}$ [15], there may have been a low level leakage into the placental circulation at the time of delivery. However, the impact of maternal contaminated blood is considered a minor source of bias.

Several mechanisms might contribute to the stimulation of the foetal immune system by maternal exposure to biocontaminants. First, a direct transfer of biocontaminants from the mother to the foetus might occur [1]. The amniotic fluid contains detectable amounts of maternal $\mathrm{IgE}, \mathrm{IgG}$, and dust mite allergen $[1,6]$. As a result, the foetal gastrointestinal tract in particular may be directly exposed to antigens or antigen-derived peptides via amniotic fluid. Secondly, biocontaminants might indirectly influence the foetal immune system by altering maternal immune reactivities. Herz et al. [9] proposed several mechanisms of prenatal regulation of foetal immunity including: transfer of antibodies, transfer of immune complexes, and transfer of cytokines or other soluble molecules via the placental membrane. Although allergenspecific maternal IgG might be a candidate for a foetal-maternal interface $[20,21]$, transplacental transfer of allergen-specific IgG was not considered to be a major mechanism for maternal regulation of allergen-specific immunity in infancy [7]. WARNER et al. [8] reported that the concentration of IL-10 in the amniotic fluid differed according to the atopy status of the mother. The authors proposed that IL-10 uptake, by swallowing amniotic fluid, may affect the developing immune responses of the foetus.

Since the associations between allergen exposure and elevated CB-IgE were found for neonates with and without a family history of atopy, hereditary risk does not act as an effect modifier. Furthermore, the present data indicate that selection effects due to allergen avoidance measures are not likely to have biased the results. The mutual adjustments for exposure to other biocontaminants, such as mite and cat allergens, as well as endotoxin, suggest that bias by these agents is also unlikely.

The role of bacterial endotoxin in postnatal development of the immune function [22] and for the development of wheeze and eczema [23] has been discussed extensively. A statistically-significant decreased risk was found for nonspecified eczema, but not for atopic eczema during the first 6 months of life [23]. The current authors do not have any plausible explanation for the decreased risk for nonspecified eczema with increased exposure to endotoxin during the first 6 months of life. For the first entire year of life, these associations attenuated, except for the risk of wheeze which remained significant. While the association between endotoxin exposure and CB-IgE was u-shaped in the present study, the association found for wheezing during the first year of life was rather linear [23]. Endotoxin may inhibit atopic (Th2) immune responses [7, 10, 12]. By activating monocytes/macrophages and stimulating the expression of costimulatory surface molecules and the production of cytokines, such as tumour necrosis factor- $\alpha$, IFN- $\gamma$ and IL-12, T-cell responses (especially Th1 responses) are activated [24]. In human pregnancy, Th1 immunity is selectively downregulated at the foeto/maternal interface [25], whereas components of the maternal innate immune system are activated [24]. It has been reported that during pregnancy, monocyte surface expression of the endotoxin receptor CD14 is increased, and that monocytes produce more IL-12 in response to endotoxin [24]. If it is assumed that maternal cytokines produced in the uterus or amnion affect the foetal immune system $[8,25,26]$, then environmental exposure to endotoxin might modulate foetal immune responses by altering the maternal cytokine profile. The present findings show a u-shaped association between perinatal exposure to endotoxin and total CB-IgE, which suggests an inhibiting effect of slightly elevated exposure to endotoxin on the production of $\operatorname{IgE}$ (at least in prenatal life). This finding supports the hypothesis that endotoxin inhibits $\mathrm{Th} 2$ responses. Interestingly, animal experiments have also shown mixed results, with studies showing both enhanced and inhibited IgE production after combined (postnatal) allergen and endotoxin exposure $[27,28]$. A recent review on environmental exposure to endotoxin suggests possible adverse as well as beneficial effects on the development of asthma and allergies [29]. The underlying mechanisms are currently only poorly understood and require further study.

A recent publication by RIEDLER et al. [30] also indicates effects of prenatal exposures. Exposure of mothers during pregnancy to stables was associated with less allergy and asthma in their infants. The range of endotoxin exposure of the current study seems to be smaller compared to other studies [31, 32]. However, the comparability of endotoxin concentrations in house dust is limited, since these studies used dust from floors, particularly from the kitchen, which is known to show higher endotoxin levels than mattress dust.

Since the current study population, with complete data including CB-IgE data, consisted of 1,332 newborns, the newborns were catorgorised into four groups. However, in the study by GeHRING et al. [23], the larger study population of 1,884 infants was split into five groups.

Measurements in the mothers' mattress dust samples taken 3 months after birth were used as proxies for prenatal exposure to biocontaminants. This may have led to exposure misclassification in homes where the age of the mothers' mattress was $<3$ months, potentially resulting in an underestimation of the effect estimates.

In conclusion, the current results show the effects of perinatal exposure to cat and mite allergens and to bacterial endotoxin on cord blood-immunoglobulin E levels, and support the hypothesis that prenatal allergen exposure and endotoxin-modulated maternal cytokines may affect the activity of foetal immune cells.

Acknowledgements. The authors would like to thank the families for their participation. The contribution of the following members of the LISA study group is acknowledged: H.E. Wichmann, J. Heinrich, G. Bolte, P. Belcredi, 
B. Jacob, A. Schoetzau, M. Mosetter, J. Schindler, A. Höhnke (Institute of Epidemiology, GSF-National Research Centre for Environment and Health, Neuherberg, Germany); M. Borte, R. Schulz, G. Sierig, K. Mirow, C. Gebauer, B. Schulze, J. Hainich (Dept of Paediatrics, University of Leipzig, Leipzig, Germany); U. Sack, F. Emmrich (Institute of Clinical Immunology and Transfusion Medicine); A. von Berg, B. Schaaf, C. Scholten, C. Bollrath (Dept of Paediatrics, Marien-Hospital Wesel, Wesel, Germany); O. Herbarth, U. Diez, I. Lehmann, M. Rehwagen, U. Schlink (Dept of Human Exposure Research and Epidemiology, UFZ-Centre for Environmental Research Leipzig-Halle Ltd, Leipzig, Germany); M. Weiss, M. Albert (Division of Paediatric Infectious Diseases and Immunology, Dr von Haunersches Kinderspital, Ludwig-Maximilians-University, Munich, Germany); B. Fahlbusch (Institute of Clinical Immunology Friedrich-Schiller-University, Jena, Germany); W. Bischof, A. Koch (Institute of Occupational, Social and Environmental Medicine).

\section{References}

1. Jones CA, Holloway JA, Warner JO. Does atopic disease start in foetal life? Allergy 2000; 55: 2-10.

2. Warner JA, Jones AC, Miles EA, Warner JO. Prenatal sensitisation. Pediatr Allergy Immunol 1996; 7: 98-101.

3. Prescott SL, Macaubas C, Holt BJ, et al. Transplacental priming of the human immune system to environmental allergens: universal skewing of initial $\mathrm{T}$ cell responses toward the $\mathrm{Th} 2$ cytokine profile. J Immunol 1998; 160: 4730-4737.

4. Szepfalusi Z, Lobihler C, Pichler J, Reisenberger K, Ebner C, Urbanek R. Direct evidence for transplacental allergen transfer. Pediatr Res 2000; 48: 404 407.

5. Szepfalusi Z, Pichler J, Elsädder S, et al. Transplacental priming of the human immune system with environmental allergens can occur early in gestation. J Allergy Clin Immunol 2000; 106: 530-536.

6. Holloway JA, Warner JO, Vance GH, Diaper ND, Warner JA, Jones CA. Detection of house-dust-mite allergen in amniotic fluid and umbilical-cord blood. Lancet 2000; 356: 1900-1902.

7. Prescott SL, Holt PG, Jenmalm M, Bjorksten B. Effects of maternal allergen-specific IgG in cord blood on early postnatal development of allergen-specific T-cell immunity. Allergy 2000; 55: 470-475.

8. Warner JA, Jones CA, Williams TJ, Warner JO. Maternal programming in asthma and allergy. Clin Exp Allergy 1998; 28: 35-38.

9. Herz U, Joachim R, Ahrens B, Scheffold A, Radbruch A, Renz H. Prenatal sensitization in a mouse model. Am J Respir Crit Care Med 2000; 162: S62-S65.

10. Martinez FD, Holt PG. Role of microbial burden in aetiology of allergy and asthma. Lancet 1999; 354: SII12-SII15.

11. von Mutius E, Braun-Fahrlander C, Schierl R, et al. Exposure to endotoxin or other bacterial components might protect against the development of atopy. Clin Exp Allergy 2000; 30: 1230-1234.

12. Gereda JE, Leung DY, Thatayatikom A, et al. Relation between house-dust endotoxin exposure, type $1 \mathrm{~T}$-cell development, and allergen sensitisation in infants at high risk of asthma. Lancet 2000; 355: 1680-1683.

13. Bergmann RL, Edenharter G, Bergmann KE, et al. Predictability of early atopy by cord blood-IgE and parental history. Clin Exp Allergy 1997; 27: 752-760.

14. Fahlbusch B, Heinrich J, Gross I, Jager L, Richter K, Wichmann HE. Allergens in house-dust samples in Germany: results of an East-West German comparison. Allergy 1999; 54: 1215-1222.

15. Ownby DR, McCullough J, Johnson CC, Peterson EL. Evaluation of $\operatorname{IgA}$ measurements as a method for detecting maternal blood contamination of cord blood samples. Pediatr Allergy Immunol 1996; 7: 125-129.

16. Heinrich J, Gehring U, Douwes J, et al. Pets and vermin are associated with high endotoxin levels in house dust. Clin Exp Allergy 2001; 31: 1839-45.

17. Hastie TJ, Tibshirani RJ. Generalized additive models. London, Chapman and Hall, 1990.

18. Jones AC, Miles EA, Warner JO, Colwell BM, Bryant TN, Warner JA. Fetal peripheral blood mononuclear cell proliferative responses to mitogenic and allergenic stimuli during gestation. Pediatr Allergy Immunol 1996; 7: 109-116.

19. King CL, Malhotra I, Mungai P, et al. B cell sensitization to helminthic infection develops in utero in humans. J Immunol 1998; 160: 3578-3584.

20. Palfi M, Selbing A. Placental transport of maternal immunoglobulin G. Am J Reprod Immunol 1998; 39: 24-26.

21. Platts-Mills T, Vaughan J, Squillace S, Woodfolk J, Sporik R. Sensitisation, asthma, and a modified Th2 response in children exposed to cat allergen: a populationbased cross-sectional study. Lancet 2001; 357: 752-756.

22. Reed CE, Milton DK. Endotoxin-stimulated innate immunity: A contributing factor for asthma. $J$ Allergy Clin Immunol 2001; 108: 157-166.

23. Gehring U, Bolte G, Borte M, et al. Exposure to endotoxin decreases the risk of atopic eczema in infancy: A cohort study. J Allergy Clin Immunol 2002; 108: 847-854.

24. Sacks G, Sargent I, Redman C. An innate view of human pregnancy. Immunol Today 1999; 20: 114-118.

25. Holt PG, Jones CA. The development of the immune system during pregnancy and early life. Allergy 2000; 55: 688-697.

26. Gern JE, Lemanske RF, Busse WW. Early life origins of asthma. J Clin Invest 1999; 104: 837-843.

27. Wan GH, Li CS, Lin RH. Airborne endotoxin exposure and the development of airway antigen-specific allergic responses. Clin Exp Allergy 2000; 30: 426-432.

28. Tulic MK, Wale JL, Holt PG, Sly PD. Modification of the inflammatory response to allergen challenge after exposure to bacterial lipopolysaccharide. Am J Respir Cell Mol Biol 2000; 22: 604-612.

29. Liu AH. Endotoxin exposure in allergy and asthma: Reconciling a paradox. J Allergy Clin Immunol 2002; 109: 379-392.

30. Riedler J, Braun-Fahrlander C, Eder W, et al. ALEX Study Team. Exposure to farming in early life and development of asthma and allergy: a cross-sectional survey. Lancet 2001; 358: 1129-1133.

31. Park JH, Gold DR, Spiegelman DL, Burge HA, Milton DK. House dust endotoxin and wheeze in the first year of life. Am J Respir Crit Care Med 2001; 163: 322-328.

32. Michel O, Kips J, Duchateau J, et al. Severity of asthma is related to endotoxin in house dust. $\mathrm{Am}$ J Respir Crit Care Med 1996; 154: 1641-1646. 